DOI: https://doi.org/10.24127/ajpm.v10i4.4269

\title{
REGRESI PROBIT UNTUK PERBANDINGAN PENGARUH MODEL PEMBELAJARAN FLIPPED CLASSROOM DAN KOOPERATIF TIPE STAD
}

\author{
Mianzhalli Tri Yunitha', Leni Marlena ${ }^{2 *}$ \\ ${ }^{1,2 *}$ Universitas Muhammadiyah Prof. DR. HAMKA, Jakarta Timur, Indonesia \\ *Corresponding author. \\ E-mail: $\quad$ mtyunitha@gmail.com ${ }^{1)}$ \\ $\underline{\text { lenimarlena@uhamka.ac.id }}^{2 *}$
}

Received 22 September 2021; Received in revised form 04 December 2021; Accepted 21 December 2021

\begin{abstract}
Abstrak
Tujuan penelitian ini untuk mendapatkan peningkatan hasil belajar matematika setelah penerapan model pembelajaran Flipped Classroom dan STAD. Jenis penelitian yang dipakai adalah penelitian kuantitatif eksperimen semu (Quasi-Experimental). Sampel penelitian sebanyak 2 kelas yang penerapannya dengan model pembelajaran Flipped Classroom dan STAD. Data dikumpulkan dari hasil tes pada materi statistika. Analisis yang dipakai yaitu Regresi Probit. Berdasarkan analisis data dengan regresi probit diperoleh peluang keberhasilan dalam meningkatkan hasil belajar peserta didik menggunakan STAD 17,4\% lebih tinggi daripada model pembelajaran Flipped Classroom. STAD merupakan model pembelajaran yang dapat melatih peserta didik untuk berkomunikasi, berinteraksi, bekerja didalam kelompok dan bertukar pikiran dengan orang lain, sehingga dapat mengatasi beberapa kesulitan dalam proses pembelajaran.
\end{abstract}

Kata kunci Flipped classroom; kooperatif tipe STAD; regresi probit.

\begin{abstract}
The research aims of this study was to obtain an increase in mathematics learning outcomes after the application of the Flipped Classroom and STAD learning models. The type of research used is quasiexperimental quantitative research (Quasi-Experimental). The research sample consisted of 2 classes whose application was the Flipped Classroom and STAD learning model. Data were collected from test results on statistical material. The analysis used is Probit Regression. Based on data analysis using probit regression, the probability of success in improving student learning outcomes using STAD is 17.4\% higher than the Flipped Classroom learning model. STAD is a learning model that can train students to communicate, interact, work in groups, and exchange ideas with others so that they can overcome some difficulties in the learning process.
\end{abstract}

Keywords Flipped classroom; probit regression; STAD type cooperative.

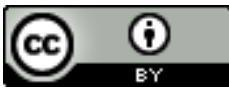

This is an open access article under the Creative Commons Attribution 4.0 International License

\section{PENDAHULUAN}

Matematika adalah salah satu ilmu yang memberikan peran andil di kehidupan sehari-hari, dimulai dari perhitungan yang mendasar sampai kita menemukan perhitungan yang abstrak dan kompleks (Mardini et al., 2019). Berdasarkan hasil terbaru Program for International Students Assessment (PISA) di tahun 2018, Indonesia mendapatkan peringkat ke -63 dari 72 negara peserta untuk di bidang Matematika (B Murtiyasa et al., 2019) dengan perolehan skor rata-rata 379 . Skor dan peringkat tersebut masih tergolong rendah, karena skor rata-rata negara anggota OECD adalah 489 (Budi Murtiyasa \& Hayuningtyas, 2020). Penyebab rendahnya peringkat Indonesia di bidang Matematika dapat 
DOI: https://doi.org/10.24127/ajpm.v10i4.4269

disebabkan oleh kemampuan matematika siswa di Indonesia rendah. Mayoritas peserta didik masih mempunyai anggapan bahwa matematika merupakan mata pelajaran yang sulit dan membosankan, sehingga banyak peserta didik yang tidak menyukai matematika. Ketidaksukaan peserta didik terhadap matematika membuat mereka sulit untuk memahami materi yang disajikan, sehingga mengakibatkan prestasi belajar matematika menjadi rendah (Ayu et al., 2021).

Terdapat beberapa model pembelajaran aktif yang berpusat kepada peserta didik untuk mendukung kegiatan pembelajaran dalam meningkatkan motivasi dan keterampilan peserta didik yang mengutamakan pada pembelajaran konseptual yaitu PBL, game based learning (Coleman \& Money, 2020), pembelajaran kooperatif (Tomlinson et al., 2016), dan flipped classroom (Jdaitawi, 2019). Pembelajaran kooperatif dan flipped classroom (FC) memiliki perbedaan dalam penerapannya. Pembelajaran kooperatif mempunyai beberapa model pembelajaran, salah satunya yaitu tipe Student Teams Achievement Division (STAD).

Kooperatif tipe STAD merupakan model pembelajaran yang menciptakan kolaborasi antara peserta didik dengan membentuk kelompok (Jahanbakhsh et al., 2019). Model ini memiliki tujuan terhadap pengaruh perilaku ketika bertukar informasi, komunikasi yang efektif serta kualitas interaksi ketika bekerjasama dan urusan perencanaan kerja (You, 2020). Hal tersebut telah dipastikan dengan adanya tes individu dan skor tim untuk melihat penguasaan tujuan dari model pembelajaran ini dengan menyusun aktivitas yang membuat anggota kelompok bekerja sama (Awada et al., 2020). Setelah kegiatan belajar tuntas, peserta didik diberikan penghargaan untuk memotivasi peserta didik dalam meningkatkan hasil belajarnya (Zairisma et al., 2020).

Model pembelajaran FC juga merupakan pembelajaran yang berpusat terhadap peserta didik. Penerapan FC berfokus kepada pemahaman materi secara mandiri sebelum kegiatan belajar mengajar dimulai (Låg \& Grøm Sæle, 2019). FC memberikan kesempatan kepada pendidik untuk memberikan pembelajaran yang aktif, serta proses pembelajaran yang tidak memberikan batasan ruang, agar siswa dapat mengatur kecepatan mereka secara interaktif ketika didalam ataupun diluar ruangan (Cevikbas \& Kaiser, 2020). Ketika di kelas, pendidik tidak hanya menerangi pembahasan yang belum dimengerti murid, tetapi memiliki peran untuk mengajak mereka berdiskusi, mengemukakan pendapat dan menyampaikan isi materi yang mereka pelajari (Jdaitawi, 2019), dan berinteraksi secara nyata dengan peserta didik lain. Melihat hasil akhir pembelajaran, dilakukan tes atau kuis untuk mengukur keberhasilan model pembelajaran (Alten et al., 2019).

Berdasarkan penelitian

Rattanatumma (2016) didapatkan hasil bahwa STAD efektif dalam meningkatkan kinerja belajar matematika peserta didik. STAD menunjukkan keunggulannya ketimbang strategi pembelajaran berbasis masalah. Adapun penelitian yang dilakukan Silitonga \& Wu (2019) menunjukkan terdapat peningkatan prestasi akademik yang terlihat dari hasil tes peserta didik. Perilaku peserta didik juga mengalami perbedaan dari sebelumnya menjadi antusias, aktif, dan 
mampu berdebat. Sejalan dengan hal tersebut, Yulianto et al (2020) menunjukkan motivasi belajar peserta didik terpengaruh secara signifikan dengan diterapkannya model pembelajaran STAD berbantu media Quizizz. STAD dapat menghadirkan suasana belajar yang baik di dalam kelas, sehingga mempengaruhi peningkatan hasil belajar siswa. Hal ini mampu membuat peserta didik lebih semangat belajar tanpa ada perbedaan. Agustini (2019) menyimpulkan bahwa penggunaan STAD memberikan suasana baru dan segar. Peserta didik menjadi lebih aktif dan termotivasi untuk mencapai nilai yang lebih baik.

Hasil penelitian $\mathrm{He}$ (2020) menunjukkan bahwa setelah diberikan perlakuan dengan FC, sikap belajar, minat, dan kebiasaan belajar peserta didik menjadi aktif, mampu belajar mandiri, kesadaran belajar kooperatif, dan tingkat kepuasan belajar di kelas FC lebih tinggi daripada kelas dengan pembelajaran konvensional. Adapun hasil penelitian yang lainnya Yousefzadeh (2015) menyatakan FC memiliki perbedaan yang signifikan dengan kelas kontrol. Peserta didik belajar memperbaiki kesalahpahaman ketika sebelumnya mempelajari sendiri materi yang diberikan dengan meningkatkan hubungan pendidik dengan peserta didik ketika pembelajaran. FC membantu peserta didik mengenali dan berpikir tentang peningkatan pemahaman mereka sendiri. Hasil penelitian lainnya dari Alten et al (2019), mengutarakan bahwa model FC mencapai hasil belajar secara signifikan lebih tinggi dari model pembelajaran yang lain dan terdapat kepuasan terhadap lingkungan belajar. Hasil penelitian yang ditemukan oleh Lee (2018) menunjukkan bahwa penggunaan model FC berdampak kepada pembelajaran aktif di kelas dan peningkatan prestasi akademik peserta didik dengan adanya atmosfer baru yang membuat peserta didik menikmati kegiatan belajar dan membuat rasa percaya diri mereka meningkat.

Kittur (2016) telah menerapkan STAD dan FC di Hubli, India. Hasil dari penelitian tersebut memperlihatkan bahwa STAD telah memotivasi dan memacu peserta didik agar dapat meningkatkan semangat belajar. FC diterapkan dengan memanfaatkan jam kelas secara efektif serta menghabiskan lebih banyak waktu untuk mendiskusikan keraguan peserta didik dan memecahkan lebih banyak masalah. Berdasarkan nilai kinerja tes dan umpan balik peserta didik, pelaksanaan kegiatan STAD dan FC telah meningkatkan nilai hasil belajar siswa.

Adapun regresi probit menjadi pilihan pada penelitian ini untuk digunakan menjadi analisis statistika. Regresi probit digunakan dengan tujuan agar dapat mengetahui peluang keberhasilan dalam meningkatkan hasil belajar dengan menggunakan dua model pembelajaran. Probit adalah model regresi yang melibatkan unit probabilitas, dikarenakan dari kata probit itu sendiri adalah singkatan dari "probability unit" (Fathurahman, 2019). Dibanding menggunakan dua nilai ratarata populasi, regresi probit dapat menghasilkan beberapa informasi (Ardianti \& Marlena, 2020).

Hasil penelitian ini akan menunjukkan peluang keberhasilan hasil belajar peserta didik pada model pembelajaran flipped classroom (FC) dibandingkan dengan kooperatif tipe STAD melalui regresi probit. Dugaan nilai peluang yang lebih besar menunjukkan bahwa model tersebut lebih baik untuk meningkatkan hasil belajar peserta didik. 
DOI: https://doi.org/10.24127/ajpm.v10i4.4269

\section{METODE PENELITIAN}

Penelitian ini menggunakan metode kuantitatif eksperimen semu dengan populasi penelitian yaitu peserta didik kelas XI SMK N 51 Jakarta. Terdapat lima program keahlian yaitu Akuntansi Keuangan Lembaga (AKL), Otomatisasi Tata Kelola Perkantoran (OTKP), Bisnis Daring Pemasaran (BDP), Multimedia (MM), Produksi dan Siaran Program Televisi (PSPT), dan Produksi Film (PF).

Dari lima program tersebut, dipilih dua program keahlian secara acak untuk dijadikan kelas penelitian. Kedua kelas yang terpilih, selanjutnya diuji kehomogenan ragamnya. Uji homogenitas dilakukan untuk melihat kehomogenitasan dari dua kelas tersebut, apakah memiliki varians data yang sama atau tidak (Mursalin et al., 2016). Hal ini penting dilakukan untuk memastikan bahwa kedua kelas homogen dan selanjutnya diberikan perlakuan yang berbeda.

Diperoleh nilai signifikansi sebesar 0,072 yang lebih besar dari alpha 5\% dari uji homogenitas yang telah diterapkan pada dua kelas. Dari hasil yang diperoleh, diputuskan untuk tidak menolak $\mathrm{H}_{0}$. Karena, nilai signifikansi yang didapat lebih besar dari alpha. Oleh karena itu, pada taraf signifikansi $5 \%$ dapat disimpulkan bahwa kelas XI MM 1 dan XI AKL 2 memiliki variansi yang homogen. Maka kedua kelas tersebut dapat dilanjutkan sebagai kelas percobaan dengan melaksanakan pembelajaran flipped classroom dan kooperatif tipe STAD pada masing-masing kelompok eksperimen untuk mendapatkan nilai hasil belajar. Adapun desain penelitian atau desain pemberian perlakuan dapat dilihat pada Tabel 1.
Tabel 1. Desain penelitian

\begin{tabular}{ccc}
\hline Kelas & Perlakuan & Observasi \\
\hline $\mathrm{E}_{1}$ & $\mathrm{X}_{1}$ & $\mathrm{O}$ \\
$\mathrm{E}_{2}$ & $\mathrm{X}_{2}$ & $\mathrm{O}$
\end{tabular}

Keterangan:

$\mathrm{E}_{1} \quad$ : Kelas eksperimen I

$\mathrm{E}_{2} \quad$ : Kelas eksperimen II

$\mathrm{X}_{1}$ : Model pembelajaran flipped classroom (FC)

$\mathrm{X}_{2}$ : Model pembelajaran kooperatif tipe student teams achievement divisions (STAD)

$\mathrm{O} \quad$ : Nilai hasil observasi

Tabel 1 menunjukkan bahwa kelas eksperimen satu memakai model pembelajaran Flipped Classroom (FC) dipraktikkan kepada kelas XI MM 1, yang dimana peserta didik harus mampu mempelajari dan memahami materi secara mandiri sebelum kegiatan pembelajaran dimulai. Maka dari itu, disediakan bahan ajar berupa video atau materi yang diunggah ke Grup WhatsApp sebelum pembelajaran dimulai. Ketika pembelajaran dimulai, pendidik dan peserta didik mendiskusikan bersama apa yang belum dipahami peserta didik dari hasil pemahaman mandiri mereka.

Lalu, kelas eksperimen dua di XI AKL 2 akan dilakukan pengajaran menggunakan kooperatif tipe Student Team Achievement Divisions (STAD). Pendidik membimbing dan merangkum materi di awal pembelajaran. Setelah itu, pendidik mengelompokkan peserta didik dengan tingkat kemampuan yang beragam. Setelah mendengar instruksi dari pendidik, peserta didik bergabung dengan kelompoknya, memahami materi dan melakukan diskusi kelompok lalu sesudahnya mereka diberi kesempatan untuk presentasi kelompok untuk melihat kemampuan pemahaman materi yang mereka punya. Masingmasing kelas eksperimen melaksanakan 
proses pembelajaran selama 2 jam dengan jumlah pertemuan 4 kali secara daring melalui platform zoom meeting. Setelah masing-masing model diterapkan, langkah terakhir yaitu peserta didik diberikan soal sesuai dengan materi yang sama ketika disampaikan disetiap kelasnya yaitu materi statistika untuk pengambilan nilai hasil belajar matematika siswa.

Sesudah peserta didik diberikan perlakuan, mereka akan mengerjakan 5 soal uraian tertulis yang sebelumnya telah lolos uji validitas dan reliabilitas. Hasil tes validitas tersebut dapat dilihat pada Tabel 2.

Tabel 2. Hasil tes validitas

\begin{tabular}{cccccc}
\hline & Soal 1 & Soal 2 & Soal 3 & Soal 4 & Soal 5 \\
\hline Skor Total & $0,525^{*}$ & $0,620^{*}$ & $0,610^{*}$ & $0,612^{*}$ & $0,471^{*}$ \\
\hline
\end{tabular}

Keterangan: ${ }^{*}$ ) signifikan pada $\alpha=5 \%$

Berdasarkan Tabel 2, nilai validitas soal 1 sampai dengan soal 5 pada skor total adalah $0,525,0,620$, $0,610,0,612$, dan 0,471 . pada taraf $5 \%$ nilai r-tabel untuk $\mathrm{n}=39$ adalah 0,316 . Karena setiap soal memiliki skor lebih dari 0,316, maka instrumen yang sudah di uji validitas layak digunakan dan peneliti dapat melanjutkan ketahap selanjutnya yaitu menguji reliabilitas soal yang dinyatakan valid. Dari hasil perhitungan reliabilitas, didapatkan nilai Cronbach's Alpha sebesar 0,626. Menurut Sugiyono (2017) jika koefisien reliabilitasnya kisaran $0,600-0,799$ soal-soal tersebut termasuk kategori kuat atau tinggi. Maka setiap soal tersebut dapat digunakan pada penelitian ini.

Setelah peserta didik diberikan perlakuan dan selanjutnya diberikan soal tes, nilai yang didapat oleh mereka akan dianalisis menjadi satu dengan regresi probit. Menurut Ardianti \& Marlena (2020) kegunaan analisis regresi probit dalam menganalisis keterkaitan variabel terikat bersifat kualitatif dan variabel-variabel bebas yang bersifat kualitatif ataupun kuantitatif. Analisis regresi probit menjelaskan fungsi persamaan menggunakan Cummulative Distribution Function (CDF) normal. Model ini mengkaji adanya hubungan satu variabel dependen dikotomi dan polikotomi dengan variabel independen (Marlena \& Nugrheni, 2019). Penelitian ini memakai variabel dummy dengan nilai 0 untuk model pembelajaran Flipped Classroom (FC), sedangkan nilai 1 untuk model pembelajaran Student Teams Achievement Divisions (STAD). Maka hasil dari variabel terikatnya akan terlihat dari bentuk persentase nilai hasil belajar matematika siswa.

Model regresi probit dapat ditulis secara umum dengan rumus persamaan: $\operatorname{probit}[\pi(x)]=\beta_{0}+\beta_{1} x_{1}+\beta_{2} x_{2}+$ $\cdots+\beta_{p} x_{p}$ dengan semua parameter regresi probit $\beta_{0}, \beta_{1}, \ldots, \beta_{p}$ dan variabel independent yaitu $x_{1}, x_{2}, \ldots, x_{p}$ (Wiley $\&$ Pace, 2015). Adapun pengujian hipotesis statistika, guna untuk melihat hubungan signifikan dari variabel independent dengan variabel dependen dengan bantuan software SPSS. Jika untuk mengetahui signifikansi koefisien $\beta$ secara parsial dengan membandingkan dugaan $\beta$ dengan standard error, maka dari dilakukan uji parsial dengan menggunakan Uji Wald (W test) (Marlena \& Nugrheni, 2019) dengan hipotesis: 
$H_{0}: \beta_{j}=0$ (tidak adanya pengaruh signifikan dari FC dan STAD untuk peningkatan hasil belajar peserta didik)

$H_{0}: \beta_{j} \neq 0$ (adanya pengaruh signifikan dari FC dan STAD untuk peningkatan hasil belajar peserta didik), dengan rumus seperti :

$$
W=\frac{\widehat{\beta}_{i}}{\operatorname{SE}\left(\widehat{\beta}_{i}\right)}
$$

Keterangan:

$\beta_{j}:$ Estimator untuk $\beta_{j}$

$S E$ : Pendugaan kesalahan standar $\beta_{j}$

Statistika uji W mengikuti distribusi normal standar dengan cara membandingkan keduanya pada taraf signifikan $\quad \alpha$. Ditolaknya $\mathrm{H}_{0}$ jika $|W|>Z_{\alpha / 2}$ atau $p-$ value $<\alpha$

Memeriksa keberartian koefisien $\beta$ dengan serentak merupakan kerja dari uji serentak, dengan Hipotesa seperti:

$H_{0}: \beta_{1}=\beta_{2}=\cdots=\beta_{p}=0 \quad ; \quad H_{1}$ : setidaknya ada satu $\beta_{j} \neq 0 ; j=1,2, \ldots, p$

Karena dalam penelitian hanya satu variabel independennya, yaitu variabel kelas, tidak dapat perbedaan pada hipotesis uji pada uji parsial, yaitu: $H_{0}: \beta_{j}=0$ (tidak adanya akibat yang relevan dari model pembelajaran FC dan STAD terhadap peningkatan hasil belajar peserta didik)

$H_{0}: \beta_{j} \neq 0$ (adanya akibat yang relevan dari model pembelajaran FC dan STAD terhadap peningkatan hasil belajar peserta didik)

Statistik uji $\mathrm{G}^{2}$ atau likelihood ratio test adalah statistika uji selanjutnya dengan rumus:

$$
G^{2}=-2 \ln \left\lceil\frac{\left(\frac{n_{1}}{n}\right)^{n_{1}}\left(\frac{n_{0}}{n}\right)^{n_{0}}}{\sum_{i=1}^{n} \widehat{\pi}_{i}^{y_{1}}\left(1-\widehat{\pi}_{1}\right)^{1-y_{1}}}\right\rceil
$$

Keterangan:

$n_{1}=$ banyaknya observasi yang diberikan nilai $\mathrm{y}=1$

$n_{0}=$ banyaknya observasi yang diberikan nilai $\mathrm{y}=0$

$n=n_{1}+n_{0}$

Membandingkan nilai statistika uji $\mathrm{G}^{2}$ dan nilai tabel chi-square dengan derajat bebas $\mathrm{v}$ yang dimana menunjukan banyaknya parameter dengan taraf signifikan $\alpha$, merupakan pengujian dari uji $G^{2}$ mengikuti distribusi chi-square. Jika nilai $p-$ value $<\alpha$ atau $G^{2}>X^{2}(v, \alpha)$ Maka $\mathrm{H}_{0}$ ditolak.

Mengetahui adanya perbedaan yang relevan antara model regresi terhadap hasil prediksi model memakai uji kesesuaian model (Goodness of Fit Test) (Permatasari, 2016) dengan hipotesis:

$H_{0}$ : Model sesuai (tidak tampak perbedaan dari model regresi dengan hasil prediksi model)

$H_{0}$ : Model tidak sesuai (tampak perbedaan antara model regresi dengan hasil prediksi model)

Statistik uji:

$$
X^{2}=\sum_{k}^{g} \frac{\left(O_{k}-n^{\prime}{ }_{k} \bar{\pi}_{k}\right)^{2}}{n_{k}^{\prime} \bar{\pi}_{k}\left(1-\bar{\pi}_{k}\right)}
$$

Keterangan:

$\mathrm{O}_{\mathrm{k}}=$ jumlah nilai variabel respon pada pengamatan ke-k

$\bar{\pi}_{k}=$ perkiraan probabilitas rata-rata

$\mathrm{g}=$ jumlah pengamatan

$n^{\prime}{ }_{k}=$ jumlah subjek pada pengamatan ke-k

Jika nilai $X^{2}>X_{(\alpha,}^{2}$ g -2$) \quad$ atau $p-$ value $<\alpha$.

\section{HASIL DAN PEMBAHASAN}

Hasil yang didapat melalui tes akhir hasil belajar siswa mata pelajaran statistika, terdapat rata-rata nilai dari kedua kelas eksperimen dengan 
perolehan pada kelas FC yaitu 62,63, sedangkan kelas STAD adalah 80,13 dengan selisih nilai 17,5. Dari pemakaian kedua model pembelajaran tersebut rata-rata nilai kelas yang menjalankan model pembelajaran STAD lebih tinggi dibandingkan kelas dengan model pembelajaraan Flipped Classroom, terlihat pada Gambar 1.

Setelah didapat rata-rata nilai hasil belajar dari masing-masing model pembelajaran FC dan kooperatif tipe STAD, selanjutnya data yang didapat dianalisis dengan probit agar terlihat adanya pengaruh yang signifikan dari model yang diterapkan terhadap keberhasilan peserta didik dalam hasil belajar. Hal ini terlihat dari perhitungan yang tersedia pada Tabel 3 .

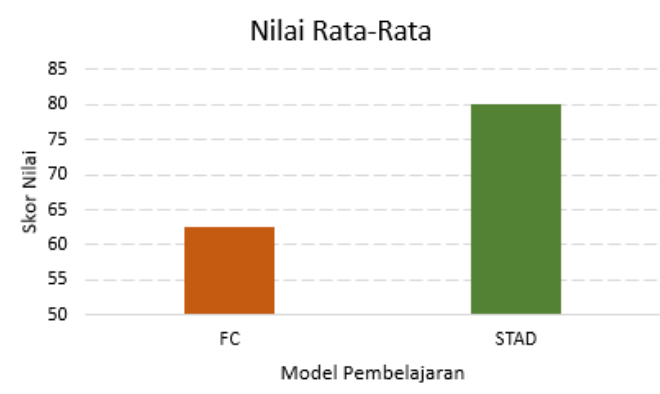

Gambar 1. Rata-rata hasil belajar model pembelajaran FC dan model pembelajaran STAD

Tabel 3. Hasil analisis probit

\begin{tabular}{ccccc}
\hline Paramater & Dugaan & Galat & $\mathbf{Z}$ & Signifikansi \\
\hline Model Pembelajaran & 0,524 & 0,032 & 16,400 & 0,000 \\
Intersep & 0,322 & 0,021 & 15,140 & 0,000 \\
\hline
\end{tabular}

Pada Tabel 3 hasil analisis probit, menjelaskan yang didapat dari perhitungan regresi probit dengan perolehan Probit $=0,322+$ 0,524(Model Pembelajaran), yang didapat dari rumus Probit $=$ Intercept + $B X$. Hasil uji parsial ini menyatakan variabel independen terhadap taraf alpha 5\% menunjukkan hasil yang signifikan. Jadi, dapat dikatakan, variabel dummy "model pembelajaran" memiliki pengaruh yang signifikan terhadap probabilitas keberhasilan peserta didik dalam hasil belajar pada bagian pengujian parsial ini. Lalu dilanjutkan untuk perhitungan regresi probit seperti yang telah disajikan pada Tabel 4.

Tabel 4. Perhitungan Regresi Probit

\begin{tabular}{cccc}
\hline $\begin{array}{c}\text { Model } \\
\text { Pembelajaran }\end{array}$ & $\begin{array}{c}\text { Probit }=\mathbf{0 , 3 2 2}+\mathbf{0 , 5 2 4} \times(\text { model } \\
\text { pembelajaran })\end{array}$ & Peluang & Persentase \\
\hline FC & $=0,322+(0,524 \times 0)=0,322$ & 0,62552 & $62,55 \%$ \\
\hline STAD & $=0,322+(0,524 \times 1)=0,846$ & 0,79955 & $79,95 \%$
\end{tabular}

Tabel 4 memperlihatkan hasil nilai probit untuk FC adalah 0,322 sedangkan STAD adalah 0,846. Adapun hasil probability dengan menggunakan Tabel Probabilitas Kumulatif Normal Standar. Perolehan pada model pembelajaran $\mathrm{FC} Z=0,322$ dengan probabilitas kumulatif sekitar $62,55 \%$ dan pada model pembelajaran STAD perolehan nilai $\mathrm{Z}=0,846$, probabilitas kumulatif sekitar 79,95\%. Dari setiap probabilitas keberhasil yang didapat pada setiap model pembelajaran dengan perolehan FC $62,55 \%$ dan STAD 
DOI: https://doi.org/10.24127/ajpm.v10i4.4269

79,95\% terhadap hasil belajar matematika peserta didik. Dari hasil yang diperoleh, menunjukkan pembelajaran dengan model kooperatif tipe STAD mempunyai probabilitas keberhasilan 17,4\% lebih dominan dari model pembelajaran FC dalam meningkatkan hasil belajar matematika peserta didik. Berikutnya dilanjutkan dengan perhitungan tes omnibus untuk melihat hipotesis yang diperoleh dengan hasil seperti yang tertulis pada Tabel 5 .

Tabel 5. Tes omnibus

\begin{tabular}{ccc}
\hline $\begin{array}{c}\text { Likelihood Ratio } \\
\text { Chi-square }\end{array}$ & df & Sig. \\
\hline 987,825 & 70 & 0,000 \\
\hline
\end{tabular}

Dari Tabel 5 menunjukkan bahwa nilai signifikansi yang diperoleh adalah $0,000<0,05$, sehingga $\mathrm{H}_{0}$ ditolak dalam uji kesesuaian model. Artinya, pada taraf 5\% dapat disimpulkan bahwa model regresi probit pada kelas variabel independen cocok untuk mengestimasi nilai probit hasil belajar siswa.

Hasil memperlihatkan bahwa model pembelajaran kooperatif tipe STAD dibandingkan dengan FC lebih unggul dalam meningkatkan hasil belajar peserta didik. Sejalan dengan penelitian Silitonga \& Wu (2019), dengan diterapkannya STAD sebagai model pembelajaran membuat suasana ketika belajar mengajar menjadi lebih hidup. Menurut Budi Murtiyasa \& Hayuningtyas (2020) menyampaikan adanya kreativitas peserta didik atas hasil belajar matematika. Peserta didik yang mempunyai kreativitas yang diatas rata-rata mendapatkan hasil belajar matematika yang lebih baik daripada peserta didik yang memiliki kreativitas dibawah rata-rata. Adapun sesuai dengan yang disampaikan oleh Bhat et al (2020) peserta didik lebih antusias terhadap pembelajaran dan pemahaman secara berkelompok, daripada belajar secara mandiri di luar jam pelajaran dalam meningkatkan hasil belajar peserta didik pada mata pelajaran matematika. Hasil penelitian ini juga senada dengan Hawa et al (2020) bahwa dengan model STAD peserta didik dapat mendiskusikan materi yang belum dipahami secara bersama-sama dengan pembagian anggota kelompok secara heterogen. Pemilihan anggota kelompok dipilih dengan cara menyatukan peserta didik yang mendapat hasil belajar yang tergolong rendah, menengah, dan tinggi (Tomlinson et al., 2016). Sehingga peserta didik dengan penguasaan materi diatas rata-rata dapat membantu anggota kelompoknya untuk membahas dan mempelajari materi yang diberikan. Pada penelitian ini, ketika diskusi kelompok lebih memanfaatkan fitur dari zoom meeting yaitu breakout rooms untuk memudahkan berdiskusi antar kelompok dan pendidik masih dapat memantau jalannya diskusi peserta didik (Correia et al., 2020).

\section{KESIMPULAN DAN SARAN}

Menurut hasil penelitian yang sudah didapat membuktikan bahwa model pembelajaran Kooperatif tipe STAD lebih baik daripada flipped classroom dengan pencapaian hasil yang signifikan mempengaruhi hasil belajar peserta didik. Flipped Classroom memiliki peluang keberhasilan hasil belajar peserta didik $17,4 \%$ lebih rendah daripada Kooperatif tipe STAD. Rata-rata skor pada STAD dan FC masing-masing mendapatkan 80,13 dan 62,63.

Dari hasil yang diperoleh, disarankan kepada para pengajar untuk mengaplikasikan model pembelajaran Kooperatif tipe STAD untuk membantu proses pembelajaran. Model pembelajaran ini signifikan dalam 
peningkatan hasil belajar siswa. Model ini melatih peserta didik untuk berkomunikasi, berinteraksi, bekerja didalam kelompok dan bertukar pikiran dengan orang lain, sehingga dapat mengatasi beberapa kesulitan dalam proses pembelajaran (You, 2020). Maka dari itu, penerapan model pembelajaran ini sangat menentukan hasil belajar peserta didik terutama pada bidang studi matematika. Disarankan untuk penelitian selanjutnya dapat menggunakan bantuan aplikasi atau media pembelajaran yang mendukung berjalannya model pembelajaran kooperatif tipe STAD.

\section{DAFTAR PUSTAKA}

Agustini, L. (2019). Effect of Student Teamss Achievement Division ( STAD ) on Mathematical Learning Results in SDLB Surabaya. International Journal for Educational and Vocational Studies, 1(6), 554-559. https://doi.org/https://doi.org/10.29 103/ijevs.v1i6.1764

Alten, D. C. D. Van, Phielix, C., Janssen, J., \& Kester, L. (2019). Effects of fl ipping the classroom on learning outcomes and satisfaction: A metaanalysis. Educational Research Review, 28(November 2018), 1-18. https://doi.org/10.1016/j.edurev.201 9.05.003

Andrian, D., Wahyuni, A., Ramadhan, S., Novilanti, F. R. E., \& Zafrullah. (2020). Pengaruh Pembelajaran Kooperatif Tipe STAD Terhadap Peningkatan Hasil Belajar, Sikap Sosial, dan Motivasi Belajar. Jurnal Inovasi Matematika (Inomatika), 2(1), 65-75. https://doi.org/https://doi.org/10.35 438/inomatika.v2i1.163

Ardianti, U., \& Marlena, L. (2020). Probit Regression Analysis to Predict the Effect of Problem- Based Learning Model and Teams Games
Tournament Cooperative Learning Model toward Student s ' Learning. Desimal: Jurnal Matematika, 3(3), 201-210. https://doi.org/10.24042/djm

Awada, G., Burston, J., \& Ghannage, R. (2020). Effect of student team achievement division through WebQuest on EFL students' argumentative writing skills and their instructors' perceptions. Computer Assisted Language Learning, 33(3), 275-300. https://doi.org/10.1080/09588221.2 018.1558254

Ayu, S., Ardianti, S. D., \& Wanabuliandari, S. (2021). Analisis Faktor Penyebab Kesulitan Belajar Matematika. AKSIOMA: Jurnal Program Studi Pendidikan Matematika, 10(3), 1611. https://doi.org/10.24127/ajpm.v10i3 .3824

Bhat, S., Bhat, S., Raju, R., D'Souza, R., \& Binu, K. G. (2020). Collaborative learning for outcome based engineering education: A lean thinking approach. Procedia Computer Science, 172(2019), 927936. https://doi.org/10.1016/j.procs.2020 .05 .134

Cevikbas, M., \& Kaiser, G. (2020). Flipped classroom as a reform oriented approach to teaching mathematics. ZDM, 52(7), 12911305.

https://doi.org/10.1007/s11858020-01191-5

Coleman, T. E., \& Money, A. G. (2020). Student-centred digital game-based learning: a conceptual framework and survey of the state of the art. Higher Education, 79(3), 415-457. https://doi.org/10.1007/s10734019-00417-0

Correia, A., Liu, C., \& Xu, F. (2020). Evaluating videoconferencing systems for the quality of the 
DOI: https://doi.org/10.24127/ajpm.v10i4.4269

educational experience. Distance Education, 41(4), 429-452. https://doi.org/10.1080/01587919.2 020.1821607

Fathurahman, M. (2019). Pemodelan Indeks Pembangunan Kesehatan Masyarakat Kabupaten/Kota di Pulau Kalimantan Menggunakan Pendekatan Regresi Probit. Jurnal VARIAN, 2(2), 47-54. https://doi.org/10.30812/varian.v2i2 .382

Hawa, S., Istiqomah, \& Setiana, D. S. (2020). Efektivitas Model Pembelajaran STAD (Student Teams Achievement Division) terhadap Hasil Belajar Matematika. Union: Jurnal Pendidikan Matematika, 8(3), 345-355. https://doi.org/http://dx.doi.org/10.3 0738/union.v8i3.7969

He, J. (2020). Research and practice of flipped classroom teaching mode based on guidance case. Education and Information Technologies, 25(239), 2337-2352. https://doi.org/https://doi.org/10.10 07/s10639-020-10137-z

Jahanbakhsh, A. A., Aliasgarizamani, M., \& Garman, Z. (2019). CIRC and STAD in Iranian context: Through the five elements to cooperative learning of lexical collocations. Cogent Arts \& Humanities, 6(1), 117.

https://doi.org/10.1080/23311983.2 019.1692469

Jdaitawi, M. (2019). The Effect of Flipped Classroom Strategy on Students Learning Outcomes. International Journal of Instruction, 12(3), 665-680.

Kittur, J. (2016). Implementation of Student - Team - Achievement Divisions Activity and Flipped Classroom to Enhance Student Learning. Journal of Engineering Education Transformations, O(0). https://doi.org/10.16920/jeet/2016/v 0i0/85637
Låg, T., \& Grøm Sæle, R. (2019). Does the Flipped Classroom Improve Student Learning and Satisfaction? A Systematic Review and MetaAnalysis. American Educational Research Association, 5(3), 1-17. https://doi.org/10.1177/2332858419 870489

Lee, M. (2018). Flipped classroom as an alternative future class model?: implications of South Korea' $\mathrm{s}$ social experiment. Educational Technology Research and Development, 66(3), 837-857. https://doi.org/10.1007/s11423018-9587-9

Mardini, N. I., Marlena, L., \& Azhar, E. (2019). Regresi Logistik Pada Model Problem Based Learning Berbantu Software Cabri 3D. Jurnal Mercumatika, 4(1), 64-70. https://doi.org/https://doi.org/10.26 486/jm.v4i1.839

Marlena, L., \& Nugrheni, E. A. (2019). Probit Regression Analysis in Estimating the Effect of Learning Assisted by Cabri 3D on Students' Mathematical Understanding Ability. Al-Jabar: Jurnal Pendidikan Matematika. https://doi.org/10.24042/ajpm.v10i2 .4729

Mursalin, W., Bardi, S., \& Abdi, A. W. (2016). Pengaruh Penggunaan Model Pembelajaran Children Learning in Science Terhadap Hasil Belajar IPS Terpadu di SMP Negeri 1 Meureudu Kabupaten Pidie Jaya Tahun Ajaran 2015/2016. Jurnal Ilmiah Mahasiswa Pendidikan Geografi FKIP Unsyiah, 1(2), 131144.

Murtiyasa, B, Rejeki, S., Setyaningsih, R., \& Merdekawati, A. (2019). Students 'Thinking in Solving Geometric Problems Based on PISA Levels. Journal of Physics: Conference Series, 1320(1), 6-12. https://doi.org/10.1088/17426596/1320/1/012068 
Murtiyasa, Budi, \& Hayuningtyas, W. (2020). Pengaruh Strategi Pembelajaran Tipe Kooperatif dan Kreativitas Siswa Terhadap Hasil Belajar Matematika. AKSIOMA: Jurnal Program Studi Pendidikan Matematika, 9(2), 358-368. https://doi.org/https://doi.org/10.24 127/ajpm.v9i2.2765

Rattanatumma, T. (2016). Assessing the Effectiveness of STAD Model and Problem Based Learning in Mathematics Learning Achievement and Problem Solving Ability. Journal of Education and Practice, 7(12), 194-199.

Silitonga, L. M., \& Wu, T.-T. (2019). Increasing Students' Interest and Learning Achievement Using Cooperative Learning (Students Team Achievement Division) Through Edmodo. In Lecture Notes in Computer Science (including subseries Lecture Notes in Artificial Intelligence and Lecture Notes in Bioinformatics): Vol. 11937 LNCS. springer.

https://doi.org/10.1007/978-3-03035343-8 4

Sugiyono, P. D. (2017). Metode Penelitian Kuantitatif, Kualitatif dan RnD. Alfabeta.

Tomlinson, C., Moon, T., \& Callahan, C. (2016). Use of cooperative learning at the middle level: Insights from a national survey. Research in Middle Level Education Quarterly, 20(4), 37-55.

https://doi.org/10.1080/10848959.1 997.11670106

You, J. W. (2020). Investigating the effects of achievement goals on team creativity and team achievement in learning communities at a South Korean university. Higher Education, 81, 367-383.

https://doi.org/https://doi.org/10.10

07/s10734-020-00545-y
Yousefzadeh, M. (2015). The Effect of Flipped Learning ( Revised Learning ) on Iranian S tudents , Learning Outcomes. Advances in Language and Literary Studies, 6(5), 209-213. https://doi.org/10.7575/aiac.alls.v.6 n.5p.209

Yulianto, I., Warsono, Nasution, \& A.P, D. B. R. (2020). The Effect of Learning Model STAD ( Student Team Achievement Division ) Assisted by Media Quizizz on Motivation and Learning Outcomes in Class XI Indonesian History Subjects at SMA Trimurti Surabaya. International Journal for Educational and Vocational Studies, 2(11), 923-927. https://doi.org/https://doi.org/10.29 103/ijevs.v2i11.2746

Zairisma, Apriliani, V., \& Yunus, J. (2020). Mathematical Representation Ability of Middle School Students through Model Eliciting Activities with STAD Type. Desimal: Jurnal Matematika, $3(2)$, 109-116. https://doi.org/10.24042/djm 